\title{
Mortality in COPD patients according to clinical phenotypes
}

This article was published in the following Dove Press journal: International Journal of COPD

\section{Rafael Golpe \\ María Suárez-Valor \\ Irene Martín-Robles \\ Pilar Sanjuán-López \\ Esteban Cano-Jiménez \\ Olalla Castro-Añón \\ Luis A Pérez de Llano}

Respiratory Medicine Service, University Hospital Lucus Augusti, Lugo, Spain
Correspondence: Rafael Golpe Servicio de Neumología, Hospital Universitario Lucus Augusti, Unidad Administrativa 4-A, c/Dr Ulises Romero I, 27002 Lugo, Spain Tel +34982 296859 Email rafael.golpe.gomez@sergas.es
Purpose: Grouping COPD subjects into clinical phenotypes might be useful for the management of the disease, but the clinical implications of such classification are still not totally clear, especially regarding prognosis. The primary objective of this study was to assess whether the mortality rates were different between four predefined clinical phenotypes.

Patients and methods: This is a retrospective, observational study carried out at the COPD clinic of a University Hospital. A total of 891 COPD patients were classified, according to the Spanish COPD guidelines, into the following four phenotypes: asthma-COPD overlap (ACO; 75 subjects), nonexacerbator (NONEX; 531 subjects), exacerbator with chronic bronchitis (EXCB; 194 subjects), and exacerbator with emphysema (EXEMPH; 91 subjects). We compared the mortality outcomes between the phenotypes.

Results: After a follow-up of $48.4 \pm 25.2$ months, there were 194 deaths $(21.8 \%)$. There were significant differences in all-cause mortality between phenotypes. The ACO phenotype had the best long-term prognosis, whereas EXEMPH had the highest risk of death. NONEX and EXCB mortality figures were in between the other two groups. We also found some differences in the causes of death, and patients with EXEMPH were at a higher risk of dying because of COPD itself. The differences in mortality did not seem related to the classification into phenotypes in itself but to disparities in COPD severity and comorbidity load between groups.

Conclusion: Classifying COPD patients according to several predefined clinical phenotypes can identify clusters of subjects with different mortality outcomes. Some phenotypes are associated with a specific cause of death. The mechanisms that underlie these differences seem to be related to COPD severity and comorbidities.

Keywords: COPD, phenotypes, mortality

\section{Introduction}

The main feature of COPD is a chronic airflow limitation caused by exposure to noxious particles and gases (especially tobacco smoke), but it is widely recognized that it is a very heterogeneous disease. ${ }^{1}$ It has been suggested that grouping patients in subgroups (phenotypes), according to a combination of attributes that relate to clinically significant outcomes (eg, exacerbations, response to therapy, and death), can help us to guide therapy and to design strategies for the management of the disease. ${ }^{2}$ Actually, some treatments for COPD are only recommended in specific phenotypes (eg, Roflumilast is indicated in patients with chronic bronchitis, frequent exacerbations, and severe ventilatory obstruction). The Spanish COPD guidelines were the first to propose a pharmacological therapeutic algorithm based on the patients' classification into the following four phenotypes: the asthma-COPD overlap (ACO), the nonexacerbator (NONEX), the frequent exacerbator with emphysema (EXEMPH), and the frequent exacerbator with chronic bronchitis $(\mathrm{EXCB}) .^{3}$ Since then, other European 
groups have adopted a similar classification, with relatively minor variations. ${ }^{4}$

The distribution of these four phenotypes and the characteristics of the patients according to them have been reported in several studies, carried out in Spain ${ }^{5,6}$ and Central and Eastern Europe. ${ }^{7}$ A recent study described the outcomes of a phenotype-based approach to classify COPD patients that used, with a few variations in the definition of ACO, the Spanish COPD guidelines. ${ }^{6}$ No significant differences were found between phenotypes in 1-year mortality, although this might have been due to the low number of deaths observed. Actually, a tendency toward differences in the mortality rates of some phenotypes (eg, ACO versus EXCB) was detected. ${ }^{6}$

Our hypothesis was that the mortality rates might differ between several COPD phenotypes in the long term. If confirmed, this finding would have relevant clinical implications, because it would help us to design specific follow-up and treatment strategies for the subjects included in the different phenotypes. The main objective of the present study was to assess the mortality rates in four different COPD phenotypes, defined with an approach based on the Spanish COPD guidelines. Secondary objectives were to study if the relative prevalence and the characteristics of the different phenotypes were similar to previous studies that used a similar classification. Also, we wanted to analyze if the causes of death were dissimilar for the different phenotypes.

\section{Patients and methods Subjects and study design}

This is a descriptive, noninterventional retrospective study, carried out at the COPD clinic of the Pulmonology Service of the University Hospital Lucus Augusti, which serves a population of 221,441 people. All the consecutive patients seen at the COPD clinic between February 2009 and June 2017 were considered for inclusion in the study. Subjects were selected from a prospectively collected database of COPD patients maintained for clinical purposes. This database systematically registers most of the study variables at the first visit. The computerized clinical records of the subjects were retrospectively reviewed. The inclusion criterion was a diagnosis of COPD based on the Global Initiative for Chronic Obstructive Lung Disease (GOLD) initiative. ${ }^{1}$ Exclusion criteria were alfa-1-antitrypsin deficiency, human immunodeficiency virus infection, concomitant diagnosis of other significant respiratory diseases (eg, interstitial lung disease, pneumoconiosis, parenchymal lung disease due to previous tuberculosis, and bronchiectasis attributed to a cause other than COPD). The index date was the date of the first visit at the COPD clinic. The following clinical and demographic data were evaluated at the index date: age, gender, body mass index (BMI), comorbidities (assessed using the Charlson index), ${ }^{8}$ dyspnea (measured by the modified Medical Research Council [mMRC] scale), moderate and severe exacerbations in the previous year (exacerbations that either required treatment with antibiotics and/or systemic steroid or required a visit to the hospital emergency room and/or hospital admission), spirometric variables, and oxygen saturation while breathing room air (measured with a finger pulse oximeter). The BMI, obstruction, dyspnea, exacerbations (BODEX) index was calculated for every patient. ${ }^{9}$ The date and cause of death were obtained from clinical records.

\section{Definition of phenotypes}

The following four clinical phenotypes were defined, according to the first version of the Spanish COPD guidelines: ${ }^{3}$ 1) NONEX: patients with less than two moderate or severe exacerbations the year before the first visit; 2) EXCB: patients with more than one moderate or severe exacerbation the year before the first visit and with cough and sputum production for at least 3 months of the year for 2 consecutive years; ${ }^{10}$ 3) EXEMPH: frequent exacerbators, as defined before, without chronic bronchitis and with radiological (computed tomography scan or chest X-ray) and/or functional (reduced CO diffusion) evidence of emphysema; and 4) ACO: two major criteria or one major criterion and two minor criteria, using a modification of the original Spanish COPD guidelines. ${ }^{3}$ Major criteria for the ACO phenotype were as follows: 1) personal history of asthma; 2) fractional exhaled nitric oxide $>40 \mathrm{ppb}$; and 3) positive postbronchodilator test with an increase of $\mathrm{FEV}_{1}>15 \%$ and $>400 \mathrm{~mL}$. Minor criteria for the ACO phenotype were as follows: 1) elevated IgE in blood; 2) personal history of atopy; and 3) positive postbronchodilator test with an increase of $\mathrm{FEV}_{1}>12 \%$ and $>200 \mathrm{~mL}$ in at least two different measurements.

\section{Statistical analyses}

Between-groups comparisons for parametric data were made using the Student's $t$-test. The Chi-square test was used for categorical data. For comparisons between more than two groups, analysis of variance test was used. Kaplan-Meier analysis with log-rank test was used for comparing survival between groups. The mean survival time was estimated as the area under the survival curve in the interval 0 to $t_{\max }{ }^{11}$ Univariate and multivariate Cox proportional hazards regression models were used to analyze the relationships between 
phenotypes, mortality, and potential confounding variables such as age, gender, $\mathrm{FEV}_{1} \%$, values of the mMRC scale, BMI, and BODEX and Charlson indices. Age and BMI were coded in 1-year increments; $\mathrm{mMRC}$, BODEX, and Charlson indices were coded in 1-unit increments; and $\mathrm{FEV}_{1} \%$ was coded as a continuous variable. Gender and phenotypes were coded as nominal categorical variables. To avoid collinearity, BODEX values on one side and $\mathrm{FEV}_{1} \%, \mathrm{BMI}$, and $\mathrm{mMRC}$ values on the other side were introduced separately in the analysis. A $P$-value of $<0.05$ was considered statistically significant.

Because this is a retrospective study, which included all the subjects seen at the COPD clinic, the sample size was not calculated beforehand. The statistical power of the study was calculated to detect differences between the mortality figures of the two phenotypes with lower mortality rates and between the two phenotypes with the greatest difference between mortality rates.

The statistical software used was MedCalc Version 13.3.3.0 (MedCalc Software bvba, Ostend, Belgium).

\section{Compliance with ethical standards}

The study was performed in accordance with the 1964 Declaration of Helsinki and its later amendments, and it was approved by our ethical committee (Comité de Ética de Investigación de Galicia, Registry number: 2012/132). Written informed consent by the study participants was waived by the committee due to the retrospective nature of the study and the absence of additional procedures or additionally collected data. All personal information of the population investigated was removed prior to data analysis.

\section{Results}

A total of 952 patients met the inclusion criteria and were considered for the study. Sixty-one patients were excluded due to incomplete data on the study variables. The study population was 891 subjects. The mean follow-up was $48.4 \pm 25.2$ months. The more frequent phenotype was NONEX (531 subjects, 59.5\%), followed by EXCB (194, 21.7\%), EXEMPH (91, $10.2 \%)$, and $\operatorname{ACO}(75,8.4 \%)$. Table 1 shows the clinical and demographic characteristics of the studied subjects, classified by phenotypes. There were differences between the phenotypes in most variables. All the phenotypes had a higher percentage of males except ACO, which showed a similar proportion of males and females. Age was higher in patients with EXCB. Oxygen saturation and $\mathrm{FEV}_{1}$ were higher, and the BODEX and Charlson indices were lower in ACO and NONEX than in the other two phenotypes. The EXEMPH phenotype showed the lowest oxygen saturation and $\mathrm{FEV}_{1}$ values and the highest BODEX index values. The Charlson index was not different between EXEMPH and EXCB. BMI was higher for ACO than for EXEMPH patients, without other differences between phenotypes.

There were 194 deaths (21.8\%) during follow-up. Figure 1 shows the Kaplan-Meier survival curves. There were significant differences in survival between phenotypes (log rank test: $P=0.0005)$. The overall mean survival time was 90.8 months (95\% confidence interval [CI]: 86.9-94.6). The mean survival time for the different phenotypes were as follows: ACO, 94.5 months (95\% CI: 87.9-101.1); NONEX, 85.2 months (95\% CI: 81.9-87.6); EXCB, 80.7 months $(95 \%$ CI: 75.3-86.2); EXEMPH, 69.9 months (95\% CI: 62.4-74.4).

Table I Clinical and demographic characteristics of the studied subjects, classified by phenotypes

\begin{tabular}{|c|c|c|c|c|c|c|}
\hline Variable & $\begin{array}{l}\text { Overall, } \\
\mathbf{N}=\mathbf{8 9} 1\end{array}$ & $\begin{array}{l}\text { (I) ACO, } \\
\text { N=75 (8.4\%) }\end{array}$ & $\begin{array}{l}\text { (2) NONEX, } \\
N=53 \text { I }(59.5 \%)\end{array}$ & $\begin{array}{l}\text { (3) } E X C B, \\
N=194(21.7 \%)\end{array}$ & $\begin{array}{l}\text { (4) EXEMPH, } \\
N=91(10.2 \%)\end{array}$ & $P$-value** \\
\hline Age (years) & $69.5 \pm 9.4$ & $68.0 \pm 9.0$ & $68.5 \pm 9.5$ & $72.7 \pm 8.9^{a}$ & $69.8 \pm 8.5$ & $<0.001$ \\
\hline Males, n (\%) & 721 (80.9) & $38(50.6)$ & $433(81.5)$ & $167(86.0)$ & $78(85.7)$ & $<0.0001$ \\
\hline Oxygen saturation (\%) & $93.2 \pm 4.4$ & $94.8 \pm 2.5^{b}$ & $93.9 \pm 3.9^{b}$ & $91.8 \pm 4.9^{a}$ & $90.6 \pm 5.5^{a}$ & $<0.001$ \\
\hline $\mathrm{FEV}_{1} \%$ & $50.9 \pm 16.9$ & $56.6 \pm 12.9^{a}$ & $53.6 \pm 16.8^{a}$ & $46.4 \pm 16.2^{c}$ & $39.8 \pm 15.5^{d}$ & $<0.001$ \\
\hline FVC\% & $73.4 \pm 16.8$ & $73.4 \pm 15.9$ & $76.0 \pm 16.7^{b}$ & $67.5 \pm 15.4$ & $70.7 \pm 17.1$ & $<0.001$ \\
\hline $\mathrm{FEV}_{\mathrm{I}} / \mathrm{FVC} \%$ & $49.8 \pm 12.4$ & $55.4 \pm 10.8^{e}$ & $50.9 \pm 11.8^{f}$ & $48.8 \pm 12.7^{f}$ & $40.4 \pm 12.0^{d}$ & $<0.001$ \\
\hline GOLD I, n (\%) & $44(5.0)$ & $3(4.0)$ & $38(7.1)$ & $3(1.5)$ & I (I.0) & $<0.0001$ \\
\hline GOLD 2, n (\%) & $412(46.2)$ & $5 \mathrm{I}(68.0)$ & $268(50.4)$ & $66(34.0)$ & $26(28.5)$ & \\
\hline GOLD 3, n (\%) & $326(36.5)$ & $20(26.6)$ & $184(34.6)$ & 91 (46.9) & $31(34.0)$ & \\
\hline GOLD 4, n (\%) & $109(12.2)$ & I (I.3) & $4 \mid(7.7)$ & 34 (I7.5) & $33(36.2)$ & \\
\hline BMI $\left(\mathrm{kg} / \mathrm{m}^{2}\right)$ & $28.4 \pm 5.3$ & $29.9 \pm 4.9^{g}$ & $28.5 \pm 5.5$ & $28.5 \pm 4.9$ & $26.8 \pm 5.3$ & 0.003 \\
\hline Charlson index* & $1.9 \pm 1.3$ & $1.4 \pm 0.9^{h}$ & $1.8 \pm 1.2^{\mathrm{h}}$ & $2.2 \pm 1.5$ & $2.0 \pm 1.4$ & $<0.001$ \\
\hline BODEX index & $2.5 \pm 1.8$ & $1.7 \pm 1.3^{b}$ & $2.0 \pm 1.5^{\mathrm{b}}$ & $3.5 \pm 1.9^{c}$ & $4.3 \pm 2.1^{d}$ & $<0.001$ \\
\hline
\end{tabular}

Notes: Results are expressed as mean \pm standard deviation or as number of cases (percentage). *Nonage adjusted. $* * P$-value for comparisons between the four phenotypes. Pairwise comparisons: ${ }^{a} P<0.05$ vs $(I)$ and (2); ${ }^{b} P<0.05$ vs (3) and (4); ${ }^{c} P<0.05$ vs (I), (2), and (4); ${ }^{d} P<0.05$ vs ( $\left.I\right)$, (2), and (3); ${ }^{\text {e }}<<0.05$ vs (2), (3), and (4); ${ }^{f} P<0.05$ vs (I) and (4); $g P<0.05$ vs (4); and $\mathrm{h} P<0.05$ vs (3).

Abbreviations: ACO, asthma-COPD overlap; BMI, body mass index; BODEX, BMI, obstruction, dyspnea, exacerbations index; EXCB, exacerbator with chronic bronchitis; EXEMPH, exacerbator with emphysema; GOLD, Global Initiative for Chronic Obstructive Lung Disease; NONEX, nonexacerbator. 


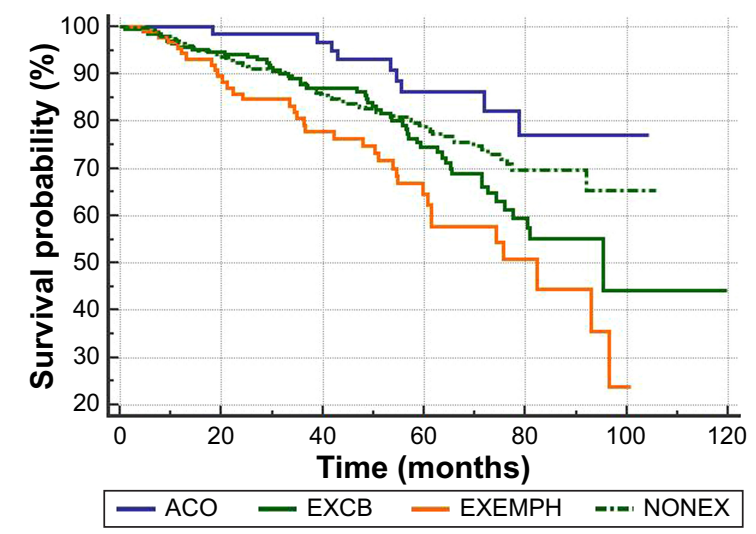

Number at risk

$\begin{array}{llllllll}\text { ACO } & 75 & 63 & 53 & 36 & 14 & 1 & 0 \\ \text { EXCB } & 194 & 174 & 130 & 73 & 28 & 3 & 0 \\ \text { EXEMPH } & 91 & 73 & 54 & 30 & 12 & 1 & 0 \\ \text { NONEX } & 531 & 429 & 306 & 174 & 51 & 4 & 0\end{array}$

Figure I Kaplan-Meier survival curves for the different phenotypes.

Abbreviations: ACO, asthma-COPD overlap; EXCB, exacerbator with chronic bronchitis; EXEMPH, exacerbator with emphysema; NONEX, nonexacerbator.

There were no significant differences in mortality between NONEX and EXCB, but all the other comparisons between phenotypes were significant. EXEMPH showed the highest mortality rates.

Table 2 shows the causes of death for the phenotypes. Patients with EXEMPH died more frequently because of exacerbation or progression of COPD, without other significant differences between phenotypes.

Tables 3 and 4 show the results of the univariate and multivariate Cox proportional hazards analyses. After adjusting for potential confounding variables, there was no longer significant relationship between the classification into phenotypes and mortality. Because the BODEX index includes exacerbations history and exacerbations are part of the definition of phenotypes, we repeated the Cox analysis replacing $\mathrm{BODEX}$ index values by the $\mathrm{BMI}, \mathrm{FEV}_{1} \%$, and $\mathrm{mMRC}$ values, with similar results (Table 4). Age, $\mathrm{FEV}_{1} \%$, values of the $\mathrm{mMRC}$ scale, BMI, and BODEX and Charlson indices were significantly correlated with a higher mortality risk.

The statistical power of the study to detect differences in mortality between ACO and NONEX phenotypes was $23.5 \%$. The power of the study to detect these differences between ACO and EXEMPH was $97.9 \%$.

\section{Discussion}

This study has shown that grouping COPD patients according to clinical phenotypes can help us to identify those with a different mortality risk. The ACO phenotype had the best long-term prognosis, whereas EXEMPH showed the highest risk of death. NONEX and EXCB phenotypes were in-between the other two, in terms of mortality risk. Also, there were some differences in the causes of death and patients with EXEMPH were at a higher risk of dying because of COPD itself. The differences in mortality seemed to be attributable to differences in COPD severity and/or comorbidities between the different phenotypes.

In the past, the therapeutic approach of COPD was essentially based on lung function. More recently, other dimensions of the disease are considered when deciding a treatment, and the current international guidelines recommend an approach based on symptoms and exacerbations. ${ }^{1}$ Due to the well-recognized clinical heterogeneity of COPD, it has been suggested that grouping patients in subgroups with

Table 2 Causes of death for the different phenotypes

\begin{tabular}{|c|c|c|c|c|c|c|}
\hline Cause of death & $\begin{array}{l}\text { Overall, } \\
\mathrm{N}=89 \text { I }\end{array}$ & $\begin{array}{l}\text { ACO, } \\
\mathrm{N}=75\end{array}$ & $\begin{array}{l}\text { NONEX, } \\
N=53 \mathrm{I}\end{array}$ & $\begin{array}{l}\text { EXCB, } \\
N=194\end{array}$ & $\begin{array}{l}\text { EXEMPH, } \\
\mathrm{N}=91\end{array}$ & $P$-value* \\
\hline COPD, ${ }^{a}$ n (\%) & $66(7.4)$ & $2(2.6)$ & $23(4.3)$ & $21(10.8)$ & $20(21.9)$ & $<0.0001$ \\
\hline Lung cancer, n (\%) & $20(2.2)$ & 0 & $13(2.4)$ & $3(1.5)$ & $4(4.3)$ & 0.24 \\
\hline Nonlung cancer, n (\%) & $27(3.0)$ & $\mathrm{I}(\mathrm{I} .3)$ & $18(3.3)$ & $6(3.0)$ & $2(2.1)$ & 0.75 \\
\hline $\mathrm{CV}, \mathrm{n}(\%)$ & $25(2.8)$ & $4(5.3)$ & $15(2.8)$ & $4(2.0)$ & $2(2.1)$ & 0.51 \\
\hline Nonrespiratory sepsis, n (\%) & $6(0.6)$ & 0 & $3(0.5)$ & $2(1.0)$ & $\mathrm{I}(\mathrm{I} .0)$ & 0.74 \\
\hline Pneumonia or respiratory sepsis, $n(\%)$ & $5(0.5)$ & 0 & $3(0.5)$ & $\mathrm{I}(0.5)$ & $\mathrm{I}(\mathrm{I} .0)$ & 0.82 \\
\hline Renal failure, $\mathrm{n}(\%)$ & $2(0.2)$ & 0 & 0 & $\mathrm{I}(0.5)$ & $\mathrm{I}(\mathrm{I} .0)$ & 0.15 \\
\hline Mesenteric ischemia, $\mathrm{n}$ (\%) & $2(0.2)$ & 0 & 0 & $2(1.0)$ & 0 & 0.06 \\
\hline Others, n (\%) & $7(0.7)$ & $\mathrm{I}(\mathrm{I} .3)$ & $5(0.9)$ & 0 & $\mathrm{I}(\mathrm{I} .0)$ & 0.55 \\
\hline Unknown, n (\%) & $34(3.8)$ & $\mathrm{I}(\mathrm{I} .3)$ & $17(3.2)$ & $13(6.7)$ & $3(3.2)$ & 0.09 \\
\hline Total, n (\%) & $194(21.7)$ & $9(12)$ & $97(18.2)$ & $53(27.3)$ & $35(38.4)$ & $<0.0001$ \\
\hline
\end{tabular}

Notes: Data are expressed as number (percentage of the whole population in each phenotype). ${ }^{\mathrm{E} E x a c e r b a t i o n ~ o r ~ p r o g r e s s i o n ~ o f ~ t h e ~ d i s e a s e . ~}{ }^{*} P$-value for comparisons between the four phenotypes.

Abbreviations: ACO, asthma-COPD overlap; CV, cardiovascular disease; EXCB, exacerbator with chronic bronchitis; EXEMPH, exacerbator with emphysema; NONEX, nonexacerbator. 
Table 3 Results of the univariate and multivariate Cox proportional hazards analyses, using BODEX index

\begin{tabular}{|c|c|c|c|c|}
\hline \multirow[t]{2}{*}{ Variable } & \multicolumn{2}{|c|}{ Univariate analysis } & \multicolumn{2}{|c|}{ Multivariate analysis } \\
\hline & HR (95\% CI) & $P$-value & HR (95\% Cl) & $P$-value \\
\hline Age & $1.06(1.04-1.08)$ & $<0.000 \mathrm{I}$ & $1.05(1.03-1.07)$ & $<0.0001$ \\
\hline Male gender & $2.57(1.62-4.08)$ & 0.0001 & $\mathrm{I} .35(0.8 \mathrm{I}-2.25)$ & 0.23 \\
\hline BODEX index & $1.48(1.38-1.57)$ & $<0.0001$ & $1.58(1.45-1.72)$ & $<0.0001$ \\
\hline Charlson index & $1.47(1.36-1.58)$ & $<0.0001$ & $1.39(1.38-1.52)$ & $<0.0001$ \\
\hline $\mathrm{EXCB}^{\mathrm{a}}$ & $2.39(1.18-4.85)$ & 0.01 & $0.51(0.24-1.09)$ & 0.08 \\
\hline NONEX ${ }^{a}$ & $1.90(1.01-3.76)$ & 0.04 & $1.37(0.67-2.80)$ & 0.38 \\
\hline EXEMPH ${ }^{a}$ & $3.67(1.76-7.63)$ & 0.0005 & $0.78(0.35-1.74)$ & 0.55 \\
\hline
\end{tabular}

Note: ${ }^{\text {TT }}$ The ACO phenotype is the reference.

Abbreviations: ACO, asthma-COPD overlap; BMI, body mass index; BODEX, $\mathrm{BMI}$, obstruction, dyspnea, exacerbations index; $\mathrm{Cl}$, confidence interval; $\mathrm{EXCB}$, exacerbator with chronic bronchitis; EXEMPH, exacerbator with emphysema; HR, hazard ratio; NONEX, nonexacerbator.

common clinical features (phenotypes) can serve to guide follow-up and therapy and to apply personalized medicine to clinical practice. However, caution has been recommended when defining phenotypes, because there is some uncertainty regarding their clinical implications. ${ }^{2}$ Some phenotypes are associated with significant outcomes: the frequent exacerbator phenotype has a worse survival, ${ }^{9}$ while subjects with ACO seem to have lower mortality than non-ACO patients. ${ }^{12}$

The Spanish COPD guidelines were pioneers in recommending a therapeutic algorithm based on four distinctive, mutually exclusive clinical phenotypes. ${ }^{3}$ However, the recommendations were essentially based on expert opinion because, when first published, the proposed phenotypes had not been fully validated. Cosío et $\mathrm{al}^{6}$ recently demonstrated that the phenotypes proposed by the Spanish guidelines (with a modification in the definition of ACO) were associated with clinically meaningful outcomes. Symptoms, lung function

Table 4 Results of the univariate and multivariate Cox proportional hazards analyses, using $\mathrm{BMI}, \mathrm{FEV}, \%$, and $\mathrm{mMRC}$ values

\begin{tabular}{|c|c|c|c|c|}
\hline \multirow[t]{2}{*}{ Variable } & \multicolumn{2}{|c|}{ Univariate analysis } & \multicolumn{2}{|c|}{ Multivariate analysis } \\
\hline & HR (95\% CI) & $P$-value & HR (95\% Cl) & $P$-value \\
\hline Age & $1.06(1.04-1.08)$ & $<0.0001$ & $1.06(1.03-1.09)$ & $<0.0001$ \\
\hline lale gender & $2.57(1.62-4.08)$ & 0.0001 & $0.87-3.22)$ & 0.11 \\
\hline BMI & $0.92(C$ & $<0.000$ I & 0.95 & 0.04 \\
\hline & & & & \\
\hline mMRC values & $2.10(1.73-2.55)$ & $<0.000 \mathrm{I}$ & $1.50(1.14-1.96)$ & 0.003 \\
\hline Charlson index & $1.47(1.36-1.58)$ & $<0.0001$ & $1.39(1.38-1.52)$ & $<0.000$ I \\
\hline $\mathrm{EXCB}^{\mathrm{a}}$ & $2.39(1.18-4.85)$ & 0.01 & $0.34(0.11-1.01)$ & 0.054 \\
\hline NONEX ${ }^{a}$ & $1.90(1.01-3.76)$ & 0.04 & $0.82(0.32-2.00)$ & 0.69 \\
\hline EXEMPH $^{a}$ & $3.67(1.76-7.63)$ & 0.0005 & $0.4 \mid(0.12-1.36)$ & 0.15 \\
\hline
\end{tabular}

Note: ${ }^{\text {aThe }} \mathrm{ACO}$ phenotype is the reference.

Abbreviations: $\mathrm{ACO}$, asthma-COPD overlap; $\mathrm{BMI}$, body mass index; $\mathrm{Cl}$, confidence interval; EXCB, exacerbator with chronic bronchitis; EXEMPH, exacerbator with emphysema; HR, hazard ratio; mMRC, modified Medical Research Council; NONEX, nonexacerbator. variables, and exacerbation rates were different between phenotypes. However, no significant differences in survival were noted between phenotypes, after 1 year of follow-up. Nevertheless, the lack of differences in mortality rates might be attributable to the low number of deaths observed within this timeframe. Actually, the authors observed significant differences between the phenotypes with lowest (ACO) and highest (EXCB) mortality rates. ${ }^{6}$

Our study, with a longer mean follow-up, has found significant differences in mortality between phenotypes. ACO patients had the best prognosis, while patients with EXEMPH had the highest mortality rates. NONEX and EXCB patients had mortality rates that lay between the other two phenotypes, without significant differences between them. We were surprised to find no differences between NONEX patients and subjects with EXCB, given the fact that exacerbations have a clear impact on survival. There are two plausible explanations for this finding. First, the study might be underpowered to detect differences between these phenotypes. Actually, there was a tendency toward a higher mortality for EXCB and the mean survival time was lower for this phenotype than for NONEX, although the differences were not statistically significant. Second, due to the retrospective design of the study, we could not assess the stability of phenotypes over time. The data were analyzed according to a classification of the patients at the index date, but the SPIROMICS study found that the exacerbator phenotype is not stable over time, and an inconsistent pattern, with years with and without exacerbations, is relatively common. ${ }^{13}$ Consequently, there could be some degree of overlap between phenotypes over time. It must be noted that in the study of Cosío et al, the EXCB phenotype had the highest mortality, while we found that survival was lowest for EXEMPH. Some differences between the study populations might account for this fact. In our study, patients with EXEMPH had lower FEV , values than EXCB, while in the study by Cosío et al, ${ }^{6}$ these phenotypes had similar $\mathrm{FEV}_{1}$ values.

We have found some significant differences in the causes of death between phenotypes. Patients with EXEMPH had a higher chance of dying because of COPD itself, either by exacerbation or by progression of the disease. This comes as no surprise, because EXEMPH patients had the worst lung function results and the highest (worst) values of the BODEX index of all the phenotypes. We found no differences in other causes of death, despite the fact that the comorbidity load was higher for the EXCB phenotype. The study is probably underpowered to produce statistically significant results about this element. 
A secondary objective of the study was to assess whether the distribution of phenotypes and the characteristics of patients in the different groups in our study were similar to three previous studies that used a similar classification..$^{5-7}$ Two of these studies were carried out in Spain, ${ }^{5,6}$ while the third was carried out in Central and Eastern Europe. ${ }^{7}$ There were noteworthy similarities between all the studies. The NONEX phenotype was the most frequent in all of them..$^{5-7}$ In our study, as well as in two of the previous studies, ${ }^{5,7}$ the following phenotypes in order of prevalence were EXCB and EXEMPH. The prevalence of ACO in these studies (6.5 and 6.9\%) was similar to our results. However, the prevalence was higher (15\%) in the study of Cosío et al, ${ }^{6}$ which used an additional criterion (blood eosinophilia) to define ACO. Actually, when Calle-Rubio et $\mathrm{al}^{5}$ made an additional analysis, using the same criteria as Cosío et al for defining ACO, the prevalence of this phenotype increased to $15.2 \%$. Lung function was more preserved in ACO and NONEX phenotypes in all the studies, including the present one..$^{5-7}$ The severity of the disease, assessed by multidimensional indices (BODE or BODEX) was also lower for ACO and NONEX phenotypes, 5,6 and our results are congruent with this finding. There were higher percentages of female patients in the ACO phenotype in the study of Koblizek et al. ${ }^{7}$ Our results are similar to Calle-Rubio et $\mathrm{al}^{5}$ in showing a similar proportion of males and females in ACO and a higher proportion of males in the other phenotypes. Cosío et $\mathrm{al}^{6}$ did not find significant differences in the distribution of genders between the different phenotypes. Regarding comorbidities, we found a higher value of the Charlson index in the EXCB phenotype. Koblizek et $\mathrm{al}^{7}$ also found higher percentages of cases with a Charlson value of $\geq 4$ in the same phenotype, while Cosío et al did not find significant differences between phenotypes.

Finally, we tried to investigate the mechanisms that underlie the differences in the mortality rates between phenotypes. It was analyzed whether these differences in mortality were attributable to the classification into phenotypes in itself or to the fact that grouping subjects into phenotypes differentiated several clusters of patients with disparities in COPD severity and/or comorbidity load. The multivariate analysis suggests that the second possibility is correct. Thus, the variations in mortality rates between the different phenotypes seem to be ascribable to between-groups differences in variables that are known to relate to mortality, such as lung function impairment, symptom burden, BMI, and comorbidities.

There are some limitations of the present study that must be acknowledged. The more important are its retrospective design and single-center setting. The sample size is relatively small, and the statistical power of the study to detect differences in mortality between some of the phenotypes was low. Also, the definition of phenotypes was based on the Spanish COPD guidelines. Although several international studies have used a similar approach, this classification is still debatable. As mentioned earlier, we classified the participants in the different phenotypes only once and we could not assess the stability of the phenotypes during all the follow-up period. As discussed previously, this circumstance is of special concern due to the fact that the exacerbator phenotype is not stable over time. This limitation could have influenced the absence of differences in mortality between EXCB and NONEX. Moreover, similar to Koblizek et $\mathrm{al}^{7}$ and Calle-Rubio et al, ${ }^{5}$ we used the first version of the Spanish COPD guidelines to define phenotypes. ${ }^{3}$ The latest Spanish COPD guidelines, published in $2017,{ }^{14}$ have modified significantly the definition of ACO, according to a consensus with representatives of the Spanish asthma guidelines. ${ }^{15}$ Due to the retrospective design of the study, we could not classify the patients according to the most recent guidelines. Another limitation is the definition of EXEMPH phenotype, which was not confirmed using computed tomography scan or carbon monoxide diffusion in every patient. In some cases, the patients were classified by means of the absence of chronic bronchitis plus evidence of air trapping in chest $\mathrm{X}$-ray. Although it has been suggested that chest X-ray can be useful for phenotyping COPD, ${ }^{16}$ there might have been some degree of overdiagnosis of the EXEMPH phenotype. Therefore, some patients in the EXEMPH might actually have an "indeterminate-exacerbator" phenotype. It must be noted that Cosío et a ${ }^{6}$ found that $2.3 \%$ of the patients in their study were frequent exacerbators that did not fulfill criteria for either chronic bronchitis or emphysema. The authors of the POPE study ${ }^{7}$ implicitly recognized this possibility, and they used the term "frequent exacerbator without chronic bronchitis" for a phenotype equivalent to EXEMPH in our study. Nevertheless, the number of patients with an indeterminate phenotype is expected to be low and it is unlikely that the results of the present study have been significantly influenced by this limitation. Finally, the study population was selected from the patients seen at the COPD clinic and not from all the patients seen at the Respiratory Medicine Service and this is a potential source of bias.

\section{Conclusion}

The results of the present study suggest that classifying COPD patients according to several predefined clinical 
phenotypes is useful to differentiate groups of subjects with different mortality risks. Also, some specific causes of death are more frequent in certain phenotypes. However, the differences in mortality rates seem to be related to the fact that this classification establishes clusters of patients with different COPD severities and/or comorbidity loads and they are not attributable to the phenotype classification in itself. Due to the limitations of the study, these results should be considered preliminary and should be confirmed with further, adequately powered prospective studies.

\section{Author contributions}

All authors contributed toward conception, design, data acquisition, analysis, and interpretation, drafting and critically revising the paper, gave final approval of the version to be published, and agree to be accountable for all aspects of the work.

\section{Disclosure}

The authors report no conflicts of interest in this work.

\section{References}

1. Global Strategy for the Diagnosis, Management and Prevention of COPD Global Initiative for Chronic Obstructive Lung Disease (GOLD). 2017. Available from: http://goldcopd.org/. Accessed November 16, 2017.

2. Han MK, Agustí A, Calverley PM, et al. Chronic obstructive pulmonary disease phenotypes. The future of COPD. Am J Respir Crit Care Med. 2010;182(5):598-604.

3. Miravitlles M, Soler-Cataluña JJ, Calle M, et al; Spanish Society of Pulmonology and Thoracic Surgery. Spanish COPD guidelines (GesEPOC): pharmacological treatment of stable COPD. Spanish Society of Pulmonology and thoracic surgery. Arch Bronconeumol. 2012;48(7):247-257.

4. Zbozinkova Z, Barczyk A, Tkacova R, et al. POPE study: rationale and methodology of a study to phenotype patients with COPD in Central and Eastern Europe. Int J Chron Obstruct Pulmon Dis. 2016;11:611-622.
5. Calle-Rubio M, Casamor R, Miravitlles M. Identification and distribution of COPD phenotypes in clinical practice according to Spanish COPD guidelines: the FENEPOC study. Int J Chron Obstruct Pulmon Dis. 2017;12:2373-2383.

6. Cosío BG, Soriano JB, López-Campos JL, et al; CHAIN Study. Distribution and outcomes of a phenotype-based approach to guide COPD management: results from the CHAIN cohort. PLoS One. 2016; 11(9):e0160770.

7. Koblizek V, Milenkovic B, Barczyk A, et al. Phenotypes of COPD patients with a smoking history in Central and Eastern Europe: the POPE study. Eur Respir J. 2017;49(5):1601446.

8. Charlson ME, Pompei P, Ales K, MacKenzie CR. A new method of classifying prognostic comorbidity in longitudinal studies: development and validation. J Chronic Dis. 1987;40(5):373-383.

9. Soler-Cataluña JJ, Martínez-García MA, Sánchez LS, Tordera MP, Sánchez PR. Severe exacerbations and BODE index: two independent risk factors for death in male COPD patients. Respir Med. 2009; 103(5):692-699.

10. American Thoracic Society. Chronic bronchitis, asthma, and pulmonary emphysema: a statement by the Committee on Diagnostic Standards for Nontuberculous Respiratory Diseases. Am Rev Respir Dis. 1962;85: $762-768$.

11. Klein JP, Moeschberger ML. Survival Analysis. Techniques for Censored and Truncated Data. 2nd ed. New York: Springer-Verlag; 2003.

12. Cosío BG, Soriano JB, López-Campos JL, et al; CHAIN Study. Defining the asthma-COPD overlap syndrome in a COPD cohort. Chest. 2016; 149(1):45-52.

13. Han MK, Quibrera PM, Carretta RG, et al. Frequency of exacerbations in patients with chronic obstructive pulmonary disease: an analysis of the SPIROMICS cohort. Lancet Respir Med. 2017;5(8):619-626.

14. Miravitlles M, Soler-Cataluña JJ, Calle M, et al. Spanish guidelines for management of chronic obstructive pulmonary disease (GesEPOC) 2017. Pharmacological treatment of stable phase. Arch Bronconeumol. 2017;53(6):324-335.

15. Miravitlles M, Álvarez-Gutiérrez FJ, Calle M, et al. Algorithm for identification of asthma-COPD overlap: consensus between the Spanish COPD and asthma guidelines. Eur Respir J. 2017;49(5):1700068.

16. Miniati M, Monti S, Stolk J, et al. Value of chest radiography in phenotyping chronic obstructive pulmonary disease. Eur Respir J. 2008; 31(3):509-514.
International Journal of COPD

\section{Publish your work in this journal}

The International Journal of COPD is an international, peer-reviewed journal of therapeutics and pharmacology focusing on concise rapid reporting of clinical studies and reviews in COPD. Special focus is given to the pathophysiological processes underlying the disease, intervention programs, patient focused education, and self management protocols.

\section{Dovepress}

This journal is indexed on PubMed Central, MedLine and CAS. The manuscript management system is completely online and includes a very quick and fair peer-review system, which is all easy to use. Visit $\mathrm{http}: / / \mathrm{ww}$.dovepress.com/testimonials.php to read real quotes from published authors. 